\title{
Pediatric cardioembolic stroke in midaortic syndrome
}

\author{
Acidente vascular cerebral cardioembólico pediátrico na síndrome da aorta média \\ Ana C. Albujaํ, Mauricio F. Villamar' ${ }^{1}$, Alejandra M. Stewart ${ }^{1}$, Donita D. Lightner ${ }^{1}$
}

A previously-healthy 18-month-old girl had a right hemibody seizure followed by prolonged hemiparesis. Blood pressure was above the $99^{\text {th }}$ percentile for her age, and it was higher in the upper extremities (UE) than in the lower extremities (LE). Femoral pulses were decreased.

Figure 1 shows the brain MRI. A transthoracic echocardiogram revealed an ejection fraction of $22 \%$, without intracardiac shunting. An abdominopelvic CT angiogram demonstrated a midaortic syndrome (Figure 2). Hypercoagulability and rheumatological studies were normal.
Midaortic syndrome is a rare disorder with stenosis of the distal thoracoabdominal aorta. Its classic triad includes abdominal bruit, elevated UE/LE blood pressure ratio, and decreased LE pulses. Most cases ( 60\%) are idiopathic. Secondary causes/associations include aortitis, atherosclerosis, neurocutaneous syndromes, and Williams syndrome. Midaortic syndrome patients can develop subarachnoid or intraparenchymal hemorrhages or, rarely, ischemic strokes ${ }^{1,2,3}$.
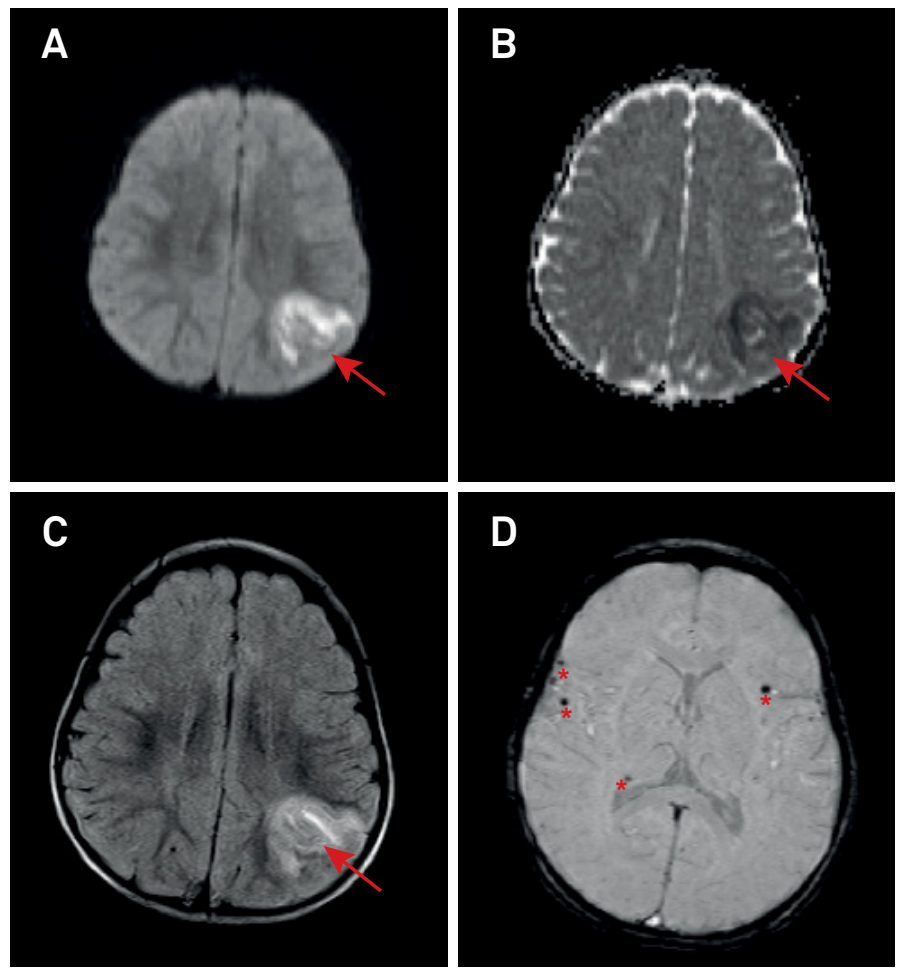

Figure 1. Neuroimaging findings: Non-contrast brain MRI shows subacute left parietal infarct (arrows) on diffusion-weighted (1A), apparent diffusion coefficient (1B), and T2-FLAIR sequences (1C). Susceptibility-weighted images reveal scattered foci of microhemorrhages (1D, asterisks). Given imaging findings consistent with embolic stroke, severely decreased left ventricle ejection fraction, lack of intracardiac shunting, normal hypercoagulability and rheumatological studies, and no other sources of emboli, the stroke mechanism is likely cardioembolic from severe systolic dysfunction. 


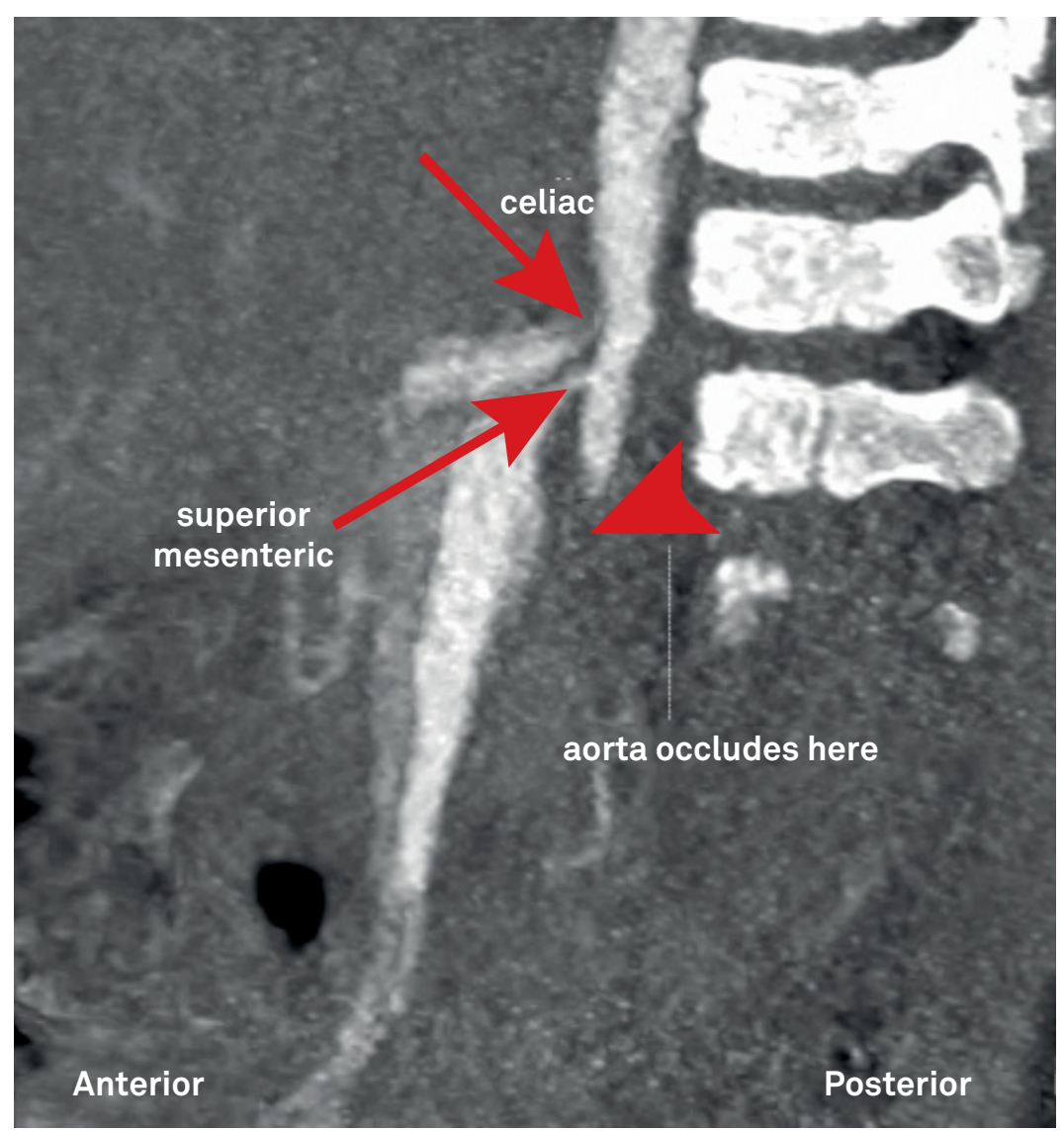

Figure 2. Midaortic syndrome: Abdominal CT angiogram shows tapering of the abdominal aorta just below the renal arteries (arrowhead), and stenosis at the origin of the celiac trunk and superior mesenteric artery (arrows).

\section{References}

1. Sethna CB, Kaplan BS, Cahill AM, Velazquez OC, Meyers KE. Idiopathic mid-aortic syndrome in children. Pediatric nephrology 2008 Jul;23(7):1135-42. https://doi.org/10.1007/s00467-008-0767-4

2. Porras D, Stein DR, Ferguson MA, Chaudry G, Alomari A, Vakili K, Fishman SJ, Lock JE, Kim HB.. Midaortic syndrome: 30 years of experience with medical, endovascular and surgical management. Pediatr Nephrol. 2013 Oct;28(10):2023-33. https://doi.org/10.1007/s00467-013-2514-8

3. Dam K1, Palen RL, Tanke RB, Schreuder MF, Jong H. Clinical recognition of mid-aortic syndrome in children. Eur J Pediatr 2013 Mar;172(3):413-6. https://doi.org/10.1007/s00431-012-1800-y 